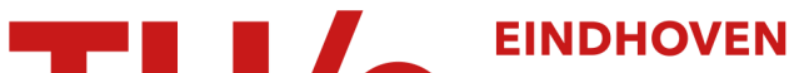 \\ UNIVERSITY OF \\ TECHNOLOGY
}

\section{On the layer sequence and morphology in solid-state displacement reactions}

\section{Citation for published version (APA):}

Loo, van, F. J. J., Beek, van, J. A., Bastin, G. F., \& Metselaar, R. (1984). On the layer sequence and morphology in solid-state displacement reactions. Oxidation of Metals, 22(3-4), 161-180. https://doi.org/10.1007/BF00656903

DOI:

10.1007/BF00656903

Document status and date:

Published: 01/01/1984

\section{Document Version:}

Publisher's PDF, also known as Version of Record (includes final page, issue and volume numbers)

\section{Please check the document version of this publication:}

- A submitted manuscript is the version of the article upon submission and before peer-review. There can be important differences between the submitted version and the official published version of record. People interested in the research are advised to contact the author for the final version of the publication, or visit the $\mathrm{DOI}$ to the publisher's website.

- The final author version and the galley proof are versions of the publication after peer review.

- The final published version features the final layout of the paper including the volume, issue and page numbers.

Link to publication

\section{General rights}

Copyright and moral rights for the publications made accessible in the public portal are retained by the authors and/or other copyright owners and it is a condition of accessing publications that users recognise and abide by the legal requirements associated with these rights.

- Users may download and print one copy of any publication from the public portal for the purpose of private study or research.

- You may not further distribute the material or use it for any profit-making activity or commercial gain

- You may freely distribute the URL identifying the publication in the public portal.

If the publication is distributed under the terms of Article $25 \mathrm{fa}$ of the Dutch Copyright Act, indicated by the "Taverne" license above, please follow below link for the End User Agreement:

www.tue.nl/taverne

\section{Take down policy}

If you believe that this document breaches copyright please contact us at:

openaccess@tue.nl

providing details and we will investigate your claim. 


\title{
On the Layer Sequence and Morphology in Solid-State Displacement Reactions
}

\author{
F. J. J. van Loo, ${ }^{*}$ J. A. van Beek, ${ }^{*}$ G. F. Bastin, ${ }^{*}$ and R. Metselaar* \\ Received April 6, 1984
}

In displacement reactions of the type $p A+B_{q} X \rightarrow q B+A_{p} X$, two main forms of the layer sequence have been found in the reaction layer, namely, $A / A_{p} X / B / B_{q} X$ and $A / B / A_{p} X / B_{q} X$. In this paper it is argued that the thermodynamics of the system, more specifically the dependence of the activity of element $X$ on the mole ratio between the elements $A$ and $B$, determines the initial layer sequence. Various morphological variants of the two basic types may develop because of the kinetics. The prediction of the layer sequence and morphology made on the basis of this theory has been verified on a number of oxidic and sulfidic systems. It is, however, pointed out that these predictions also can be applied to purely metallic ternary systems and to other types of reactions.

KEY WORDS: displacement reactions; ternary diffusion; multiphase diffusion; diffusion path; $\mathrm{Ni}-\mathrm{Cu}-\mathrm{O} ; \mathrm{Co}-\mathrm{Cu}-\mathrm{O} ; \mathrm{Fe}-\mathrm{Ni}-\mathrm{O} ; \mathrm{Fe}-\mathrm{Cu}-\mathrm{O} ; \mathrm{Cu}-\mathrm{Ni}-\mathrm{S} ; \mathrm{Fe}-\mathrm{Ni}-\mathrm{S} ; \mathrm{Cr}-\mathrm{Ni}-\mathrm{S}$.

\section{INTRODUCTION}

In our previous paper, ${ }^{1}$ we discussed for a solid-state displacement reaction of the type

$$
p A+B_{q} X \rightarrow q B+A_{p} X
$$

the layer sequence and morphology of the reaction products, starting from a planar diffusion couple $A / B_{q} X$. The results are given in Fig. 1, in which $A$ and $B$ are metals and $X$ stands for oxygen, sulfur, or any other nonionic

*Eindhoven University of Technology, Laboratory of Physical Chemistry, Eindhoven, The Netherlands. 


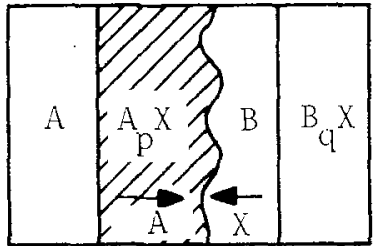

I

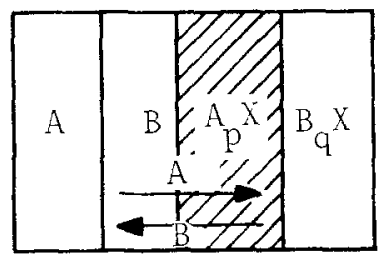

II a)

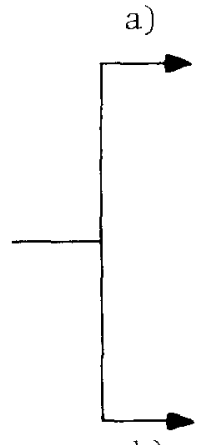

b)

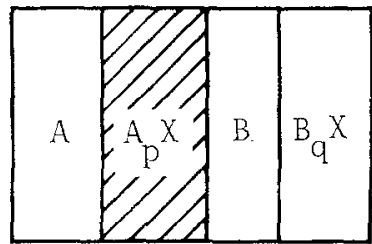

Diffusion A through $\mathrm{A}_{\mathrm{p}} \mathrm{X}$ rate determining.

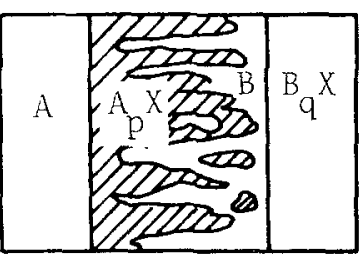

Diffusion $X$ through $B$ rate determining.
Interface $B / A_{p} X$ remains planar since element $X$ does not diffuse, only $\mathrm{A}$ and $\mathrm{B}$ exchange.

Fig. 1. Basic morphologies for the reaction zone in the displacement reaction $p A+B_{q} X \rightarrow$ $q B+A_{p} X$. Morphological variants of type II are possible (see text).

element. Rapp et $a l^{2}$ and Yurek et al. ${ }^{3}$ have treated case I extensively for oxidic systems. The starting point in their considerations was the stability of the originally planar interface $B / A_{p} X$ in case of an accidental perturbation. They have shown that the layered structure I(a) occurs if the flux of $X$ atoms through the $\mathrm{B}$ layer exceeds the flux of $A$ ions through the $A_{p} X$ layer. If the reverse is true a two-phase aggregate layer $\mathrm{I}(\mathrm{b})$ consisting of $B+A_{p} X$ will show up.

In the previous work, ${ }^{1}$ we have shown that for some sulfidic systems $\left(\mathrm{Cu} / \mathrm{Ni}_{3} \mathrm{~S}_{2}\right.$ and $\left.\mathrm{Fe} / \mathrm{Ni}_{3} \mathrm{~S}_{2}\right)$, the layer sequence II occurs. Since the element $X$ (sulfur in our case) actually stands still, only an exchange of the metals $A$ and $B$ takes place, leading to an always planar interface $B / A_{p} X$. The present paper deals with the problem that in the oxidic systems studied by Rapp et al., the initial stage of reaction shows the layer sequence $A / A_{p} X / B / B_{q} X$, whereas in the sulfidic systems we studied, this sequence 
is $A / B / A_{p} X / B_{q} X$. We have developed a model stating that this initial sequence is governed by the thermodynamics of the system, which will be demonstrated in the next section. In the closing section experimental evidence for our theory will be supplied, indicating that the model is very general indeed and applicable not only to displacement reactions but also to other types of solid-state reactions.

\section{THERMODYNAMIC CONSIDERATIONS}

We will start with an $A-B-X$ system at a temperature where the isothermal cross-section shown in Fig. 2 is valid. Figure 2a represents the normal Gibbs composition triangle, whereas in Fig. 2b, by another choice of variables a more convenient plot of the phase relations is used for our discussion. For the geometrical representation of phase equilibria we refer to the survey paper of Pelton and Schmalzried. ${ }^{4}$

We suppose a diffusivity of the elements large enough to maintain equilibrium conditions at the phase interfaces. Further we will assume a number of simplifications which, however, are not in any way essential for the discussion. So we suppose an ideal ("Henrian") behavior of the quasibinary system $A X-B X$, which allows us to determine the thermodynamic activities of $A X$ and $B X$ as a function of concentration. We also suppose an ideal behavior of the complete solid solution $(A, B)$; the solubitity of $X$ in $(A, B)$ is supposed to be very small. The thermodynamic activity $a_{X}$ as a function of the mole fraction $A$ can then be calculated. ${ }^{4}$ The basis for these calculations are the relationships

$$
\begin{aligned}
& \frac{a_{A} \cdot a_{X}}{a_{A X}}=K=a_{X}^{0}(A, A X) \\
& \frac{a_{B} \cdot a_{X}}{a_{B X}}=K^{\prime}=a_{X}^{0}(B, B X)
\end{aligned}
$$

where $a_{A}, a_{A X}$, and $a_{X}$ represent the activities of $A, A X$, and $X$ in a situation in which the phases $(A, B)$ and $A X$ are in equilibrium along a tie-line; the same holds for $a_{B}, a_{B X}$, and $a_{X}$ in Eq. (2). The activities $a_{X}^{0}$ are the values for the binary mixtures $A / A X$ and $B / B X$, respectively, which can be found from thermodynamic data like the equilibrium pressures $P_{\mathrm{O}_{2}}, P_{\mathrm{S}_{2}}$, etc.

The mole fraction $N_{A}^{*}$ of the solid solution in equilibrium with both $A X$ and $B X$ (with mole fractions $N_{A X}^{*}$ and $N_{B X}^{*}$ ) can be found from Eqs. (1) and (2) because of the ideality of the system:

$$
\frac{a_{A}}{a_{B}}=\frac{a_{A X}}{a_{B X}} \cdot \frac{a_{X}^{0}(A, A X)}{a_{X}^{0}(B, B X)}
$$



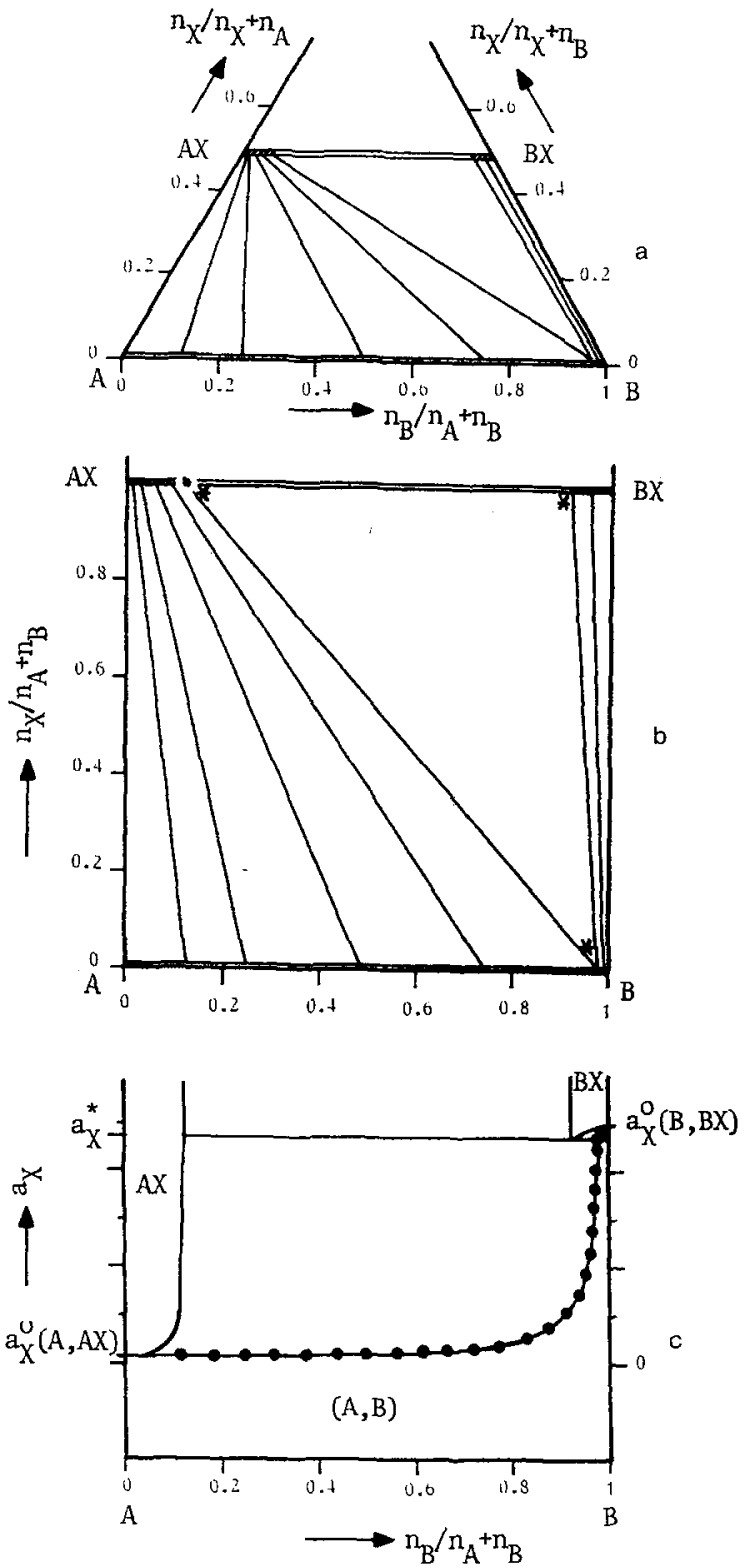

Fig. 2. (a) Phase relations in the A-B-X system represented in the so-called Gibbs triangle. (b) The same phase relations represented in a rectangular configuration by another choice of variables. (c) The activity of $X$ as a function of the metal mole ratio. The dots represent the activity of $X$ in equilibrium with the solid solution $(A, B)$. 
or

$$
\frac{N_{A}^{*}}{1-N_{A}^{*}}=\frac{N_{A X}^{*}}{N_{B X}^{*}} \cdot \frac{a_{X}^{0}(A, A X)}{a_{X}^{0}(B, B X)}
$$

The activity $a_{X}^{*}$ of $X$ in the three-phase field $(A, B)-A X-B X$ can also be found from Eqs. (1) and (2) as

$$
a_{X}^{*}=\frac{N_{A X}^{*}}{N_{A}^{*}} \cdot a_{X}^{0}(A, A X)
$$

or

$$
a_{X}^{*}=\frac{N_{B X}^{*}}{1-N_{A}^{*}} \cdot a_{X}^{0}(B, B X)
$$

Figure $2 c$ gives the activity of $X$ as a function of the mole ratio $n_{B} / n_{A}+n_{B}$. It is clear that in real systems, the same calculations can be done using the often well-known activity coefficients for the elements $A$ and $B$ in the solid solution.

Under these conditions the thermodynamic activities for the elements $A, B$, and $X$ can be calculated in a diffusion couple, if the diffusion path runs along the boundaries of the single-phase fields in the cross-section as shown in Fig. 3a. In this figure two diffusion paths have been drawn as an example, corresponding to the layer sequence $A / A X / B / B X$ (path I) and $A / B / A X / B X$ (path II). It can immediately be seen that for both paths the activity-penetration curves are the same, because both paths touch the same tie-lines in the two-phase fields $(A, B) / A X$ and $(A, B) / B X$ at any point in the couple. In Figs. $3 b$ and $c$ these curves are given for the components $A$ and $X$ for both diffusion paths (the curve for component $B$ is found by the relation $a_{B}=1-a_{A}$ ). Note the fact that the activity-penetration curves have no maximum or minimum: the activity gradients are either positive or negative along the whole diffusion direction. This implies that on purely thermodynamical grounds both paths, as well as many others, are possible in systems with this type of phase diagram.

In Figs. $4 a$ and $b$ another type of cross-section is shown. The slope of the tie-lines running from the solid solution $(A, B)$ towards $A X$ in Fig. $4 \mathrm{~b}$ has a sign opposite to those running towards the compound $B X$. This is contrary to the cross-section in Figs. $2 b$ and $3 a$ where the slope of all tie-lines connected with the solid solution $(A, B)$ has the same sign. In Fig. $4 \mathrm{c}$ the activity of the element $X$ is given as a function of the mole ratio $n_{B} / n_{A}+n_{B}$. Two extreme possibilities for the diffusion path in the couple $A / B X$ are represented in Fig. 5a, corresponding to the activity-penetration curves for the components $A$ and $X$ in Figs. 5b and c. Again, of course, these curves are essentially equal for both paths. They differ, however, from those given 

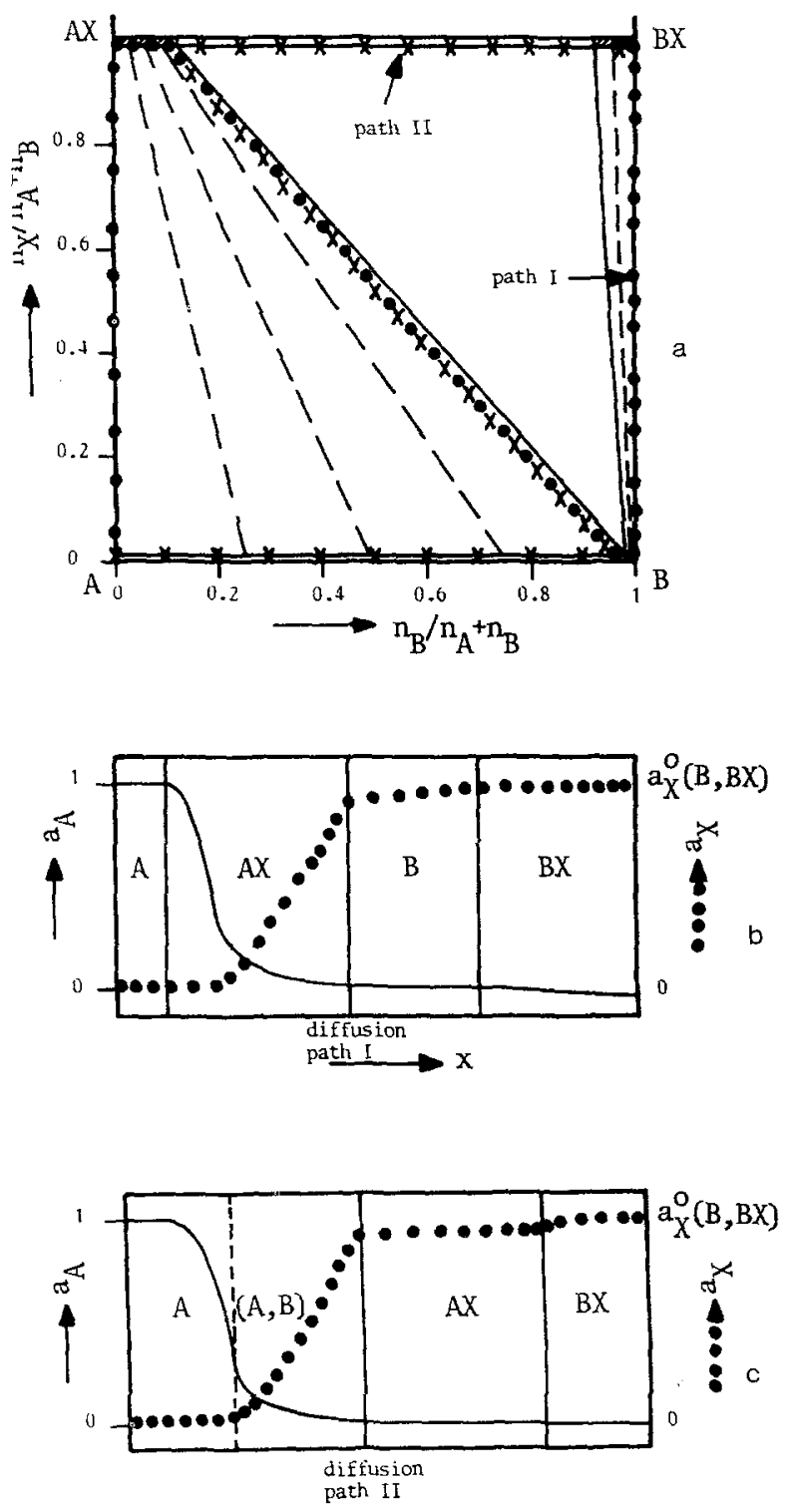

Fig. 3. (a) Phase relations in the $A-B-X$ system with two possible diffusion paths for the couple $A / B X .(b, c)$ The schematic layer sequences associated with the diffusion paths in (a), together with the activities of the elements $A$ and $X$ as a function of concentration (or distance) in the couples. Both sequences are thermodynamically allowed. 

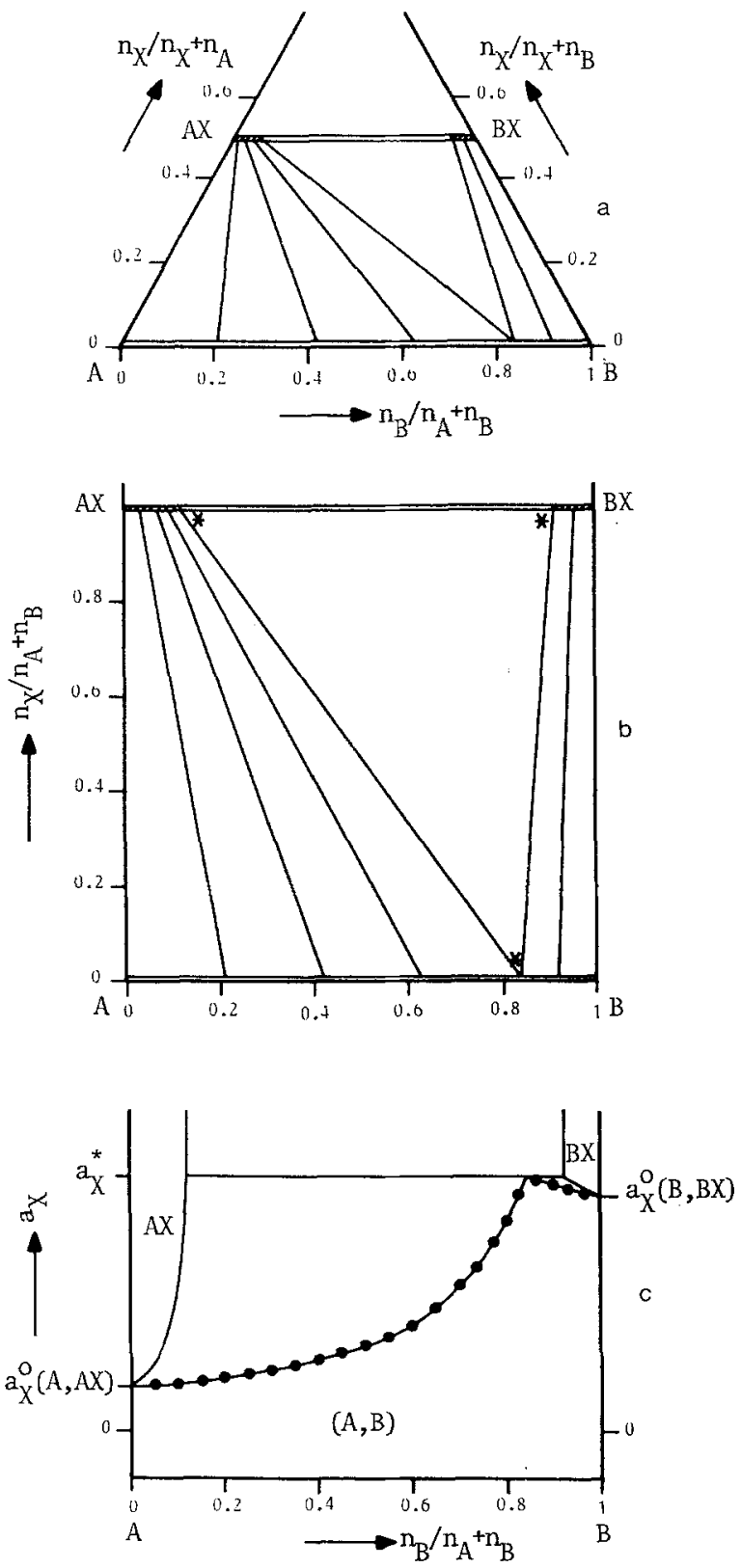

Fig. 4. (a, b) Phase relations in the $A-B-X$ system. (c) The activity of element $X$ as a function of the metal mole ratio. The dots represent the activity of $X$ in equilibrium with the solid solution $(A, B)$. 

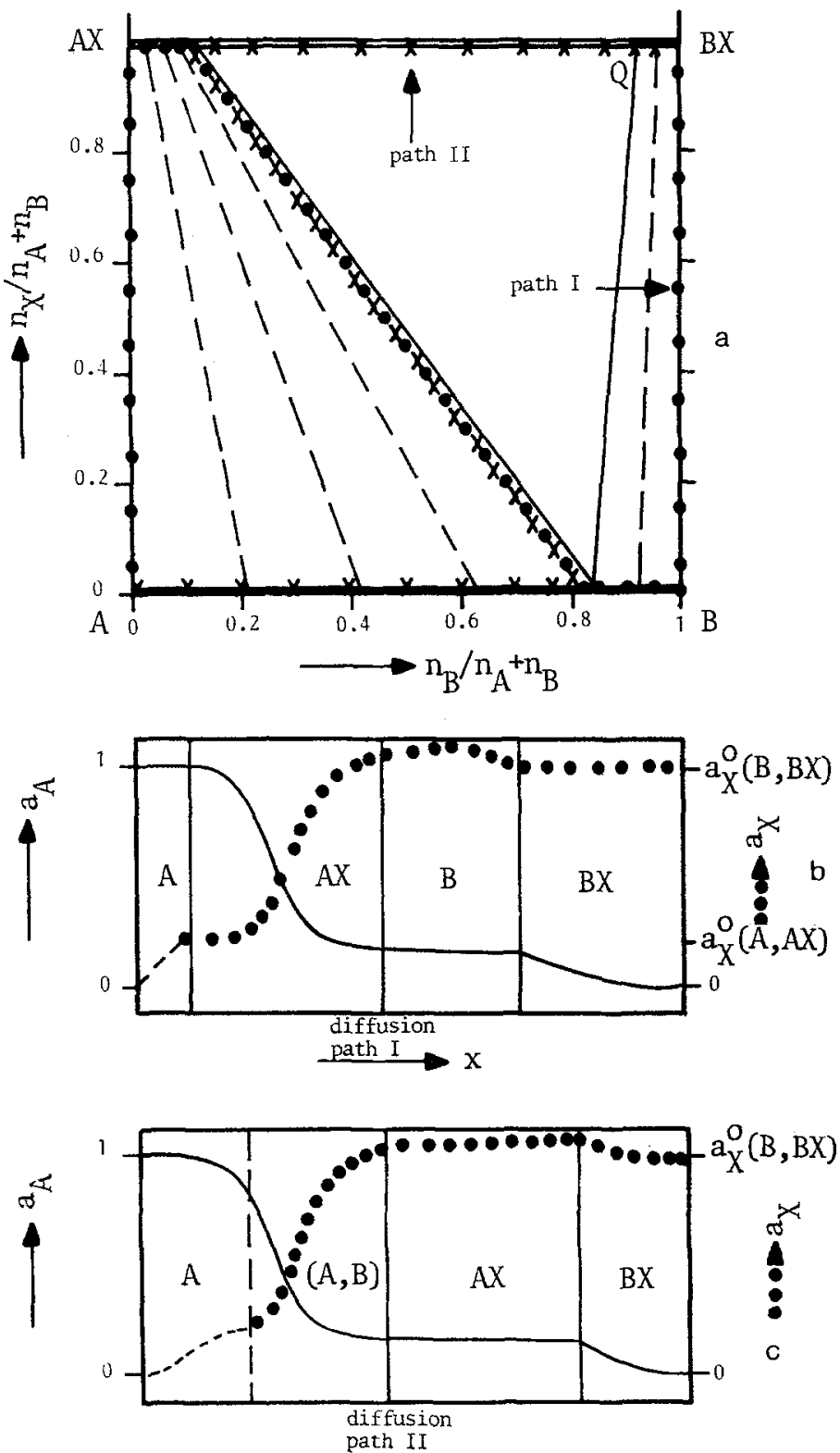

Fig. 5. (a) Phase relations in the $A-B-X$ system together with two diffusion paths for the couple $A / B X$; path $I$ is thermodynamically not allowed. (b, c) The schematic layer sequences associated with the diffusion paths in (a), together with the activities of the elements $A$ and $X$ as a function of concentration (or distance) in the couples. The layer sequence shown in (b) is thermodynamically not allowed. 
in Figs. $3 \mathrm{~b}$ and $\mathrm{c}$ by the fact that the activity of $X$ shows a maximum, corresponding to the maximum in the three-phase field $(A, B)-A X-B X$ shown in Fig. 4c.

The occurrence of this maximum is the key to our explanation of the layer sequence which will actually arise in a diffusion couple. We assume that the unimposed diffusion of an element will be in a direction in which its own activity will be lowered (see, e.g., Lane and Kirkaldy). ${ }^{5}$ For a displacement reaction of the type given in Fig. 5, the activity of element $X$ is always raised if this element diffuses, whatever layer sequence might occur. Therefore, the element $X$ will simply stand still. The reaction proceeds by an exchange of $A$ and $B$ atoms, and this creates a situation in which an activity gradient is imposed upon the "unwilling" element $X$. Therefore, in Fig. 5 diffusion path $I$ is impossible as an initial stage in the diffusion process. It is essential that the starting material $B X$ be saturated with $A X$ at the reaction interface: the diffusion path has to run from $B X$ to point $Q$. In our experiments (see below), we found for this type of phase diagram indeed only diffusion paths which met this criterion. From $Q$ to $A$ the diffusion path is thermodynamically not unambiguously defined. For instance, by short-circuit diffusion of the element $X$, precipitates of $A X$ in the $B$ layer can occur. Kinetic aspects undoubtedly will play an important role in the precise course of the diffusion path in this part of the couple.

For a phase diagram of the type given in Fig. 3, both layer sequences, $A / A X / B / B X$ and $A / B / A X / B X$, are thermodynamically allowed since in both cases all elements diffuse in the direction of decreasing their own activity. In our experiments, we found for this type of diagram only the first layer sequence as an initial stage, giving rise to morphologies as represented in Fig. 1, types Ia or Ib. Apparently, since $X$ can diffuse, a $B$ layer adjacent to the $B X$ phase is easily formed. This layer will remain and, therefore, prevent a further growth process of type II in Fig. 1. In a more general way, our model implies that in any diffusion couple the elements only intrinsically diffuse into a direction in which their own activity is lowered. This means that in experiments in which atoms appear to diffuse up their own activity gradient, this is in fact caused by the mobility of the other components. In terms of interdiffusion parameters, which only describe the actual distribution of the elements after the diffusion annealing, interdiffusion fluxes can be described which "flow up" their own activity gradient as shown, e.g., by Dayananda and Kim. ${ }^{6}$

\section{EXPERIMENTAL RESULTS}

Our experiments have been carried out on oxidic, sulfidic, and metallic ternary systems. 


\section{Oxidic Systems}

Vosters et al. ${ }^{7,8}$ investigated displacement reactions in the $\mathrm{Ni}-\mathrm{Cu}-\mathrm{O}$ and $\mathrm{Co}-\mathrm{Cu}-\mathrm{O}$ systems at $1000^{\circ} \mathrm{C}$. The results are shown in Figs. 6 and 7. The phase diagrams and diffusion paths they found experimentally are given in $6 \mathrm{a}$ and $7 \mathrm{a}$. Then the equilibrium oxygen pressure is given as a function of the metal mole fraction in $6 \mathrm{~b}$ and $7 \mathrm{~b}$. The thermodynamic data necessary to construct these and the following figures were obtained mainly from Kubaschewski et al. ${ }^{9}$ and Barin et al. ${ }^{10,11}$ The experimentally found schematic layer arrangement in the couples $\mathrm{Ni} / \mathrm{Cu}_{2} \mathrm{O}$ and $\mathrm{Co} / \mathrm{Cu}_{2} \mathrm{O}$ is shown in $6 \mathrm{c}$ and $7 \mathrm{c}$, together with the equilibrium oxygen pressure as a function of the composition (or distance) in the couples. In both cases the slope of the tie-lines running from the metal phase to the oxide phases has the same sign, and the predicted layer arrangement $A / A X / B / B X$ is indeed found. Figures 8 and 9 show the results of displacement reactions in the $\mathrm{Fe}-\mathrm{Ni}-\mathrm{O}$ and $\mathrm{Fe}-\mathrm{Cu}-\mathrm{O}$ systems at $1000^{\circ} \mathrm{C}$. Vosters ${ }^{8}$ determined the phase relations in these systems. Again the slope of all the relevant tie-lines has the layer arrangement is indeed of the type $A / B / A X / B X$, although by predicted from our model. The experiments of Laheij et al. ${ }^{12}$ on displacement reactions in the $\mathrm{Fe}-\mathrm{Cr}-\mathrm{O}$ system also fit within this type.

\section{Sulfidic Systems}

In our previous paper, ${ }^{1}$ we reported on experiments in the $\mathrm{Cu}-\mathrm{Ni}-\mathrm{S}$ and $\mathrm{Fe}-\mathrm{Ni}-\mathrm{S}$ systems. In Figs. 10, 11, and 12, the results are schematically summarized. The slope of the relevant tie-lines varies from negative to positive going to more Ni-rich compositions. In agreement with this sign transition and the necessarily occurring maximum in the sulfur pressure, the layer arrangement is indeed of the type $A / B / A X / B X$, although by short-circuit diffusion of sulfur, small sulfide precipitates in the metal layer occur.

Some experiments have also been carried out on the reaction between $\mathrm{Cr}$ and $\mathrm{Ni}_{3} \mathrm{~S}_{2}$ at $500^{\circ} \mathrm{C}$. The phase diagram in Fig. 13a is mainly taken from the work of Kirkaldy et al..$^{13}$ at $600^{\circ} \mathrm{C}$ with some adjustments on the basis of our own measurements and of the binary diagram of Ni-S. ${ }^{14}$ The slope of the tie-lines is always negative. The layer arrangement found by us is of the type $A / A X+B / B X$. Relevant diffusion data on this system are not known at $500^{\circ} \mathrm{C}$, so the kinetic criterion of Rapp concerning the occurrence of this layer arrangement cannot be verified at the moment. Obviously the flux of $\mathrm{Cr}$ ions through the $\mathrm{Cr}_{1-x} \mathrm{~S}$ layer has to be larger than the flux of sulfur through the Ni layer in order to create this aggregate morphology. This is strongly supported by the observation of rather thick $\mathrm{Cr}_{1-x} \mathrm{~S}$ layers during the sulfidation of $\mathrm{CrNi}$ alloys at $700^{\circ} \mathrm{C}$ by Kirkaldy et al. ${ }^{13}$ and the very low diffusion coefficient of $\mathrm{S}$ in $\mathrm{Ni}$ at $680^{\circ} \mathrm{C}$ as given by Shatinsky et al..$^{15}$ 

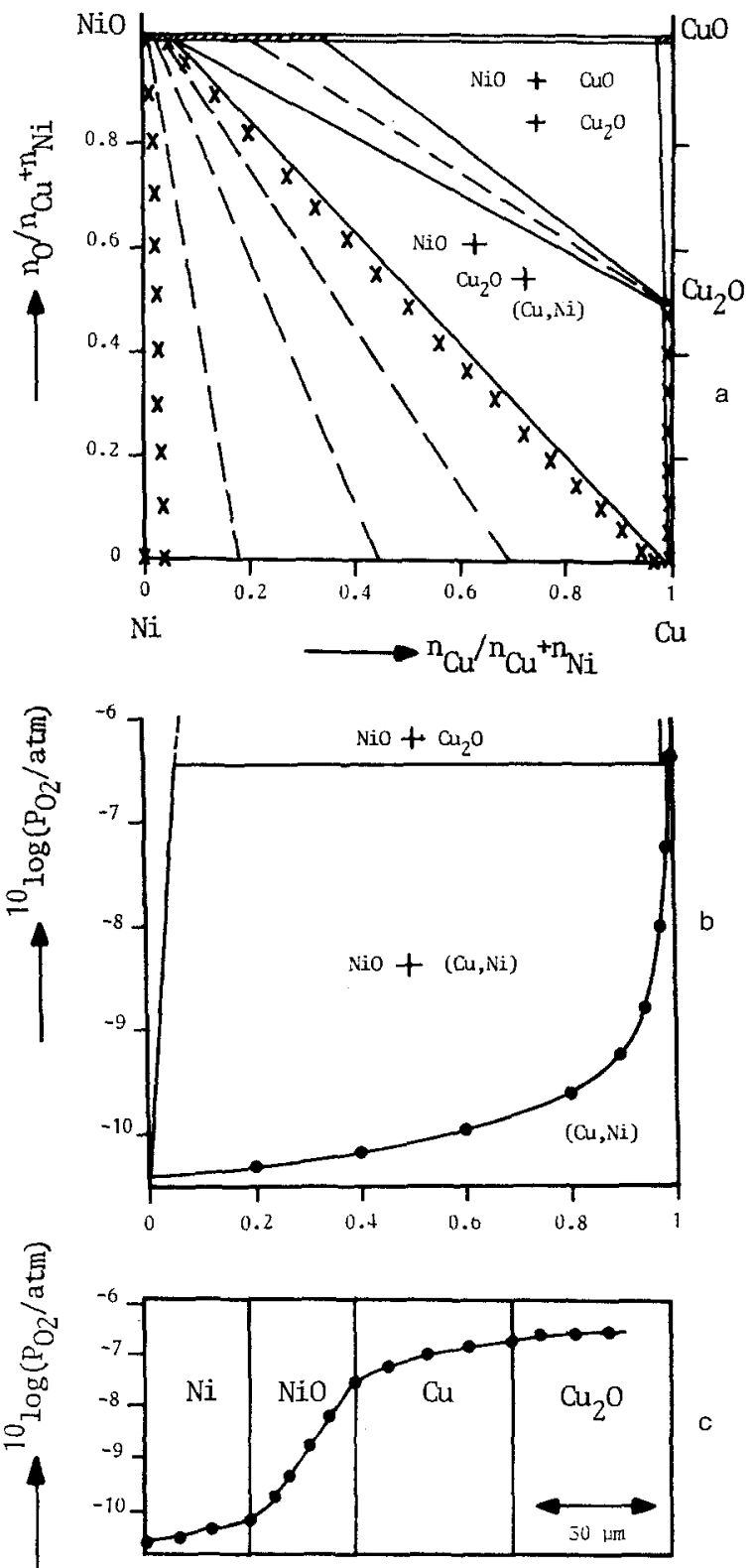

Fig. 6. (a) Phase relations and diffusion path in the $\mathrm{Ni}-\mathrm{Cu}-$ $\mathrm{O}$ system at $1000^{\circ} \mathrm{C}$. (b) The oxygen pressure as a function of the metal mole ratio. The dots represent the oxygen pressure in equilibrium with the solid solution $(\mathrm{Cu}, \mathrm{Ni})$. (c) A schematic representation of the layer morphology and equilibrium oxygen pressure in the couple $\mathrm{Ni} / \mathrm{Cu}_{2} \mathrm{O}$ after a heat treatment of $100 \mathrm{hr}$ at $1000^{\circ} \mathrm{C}$. 

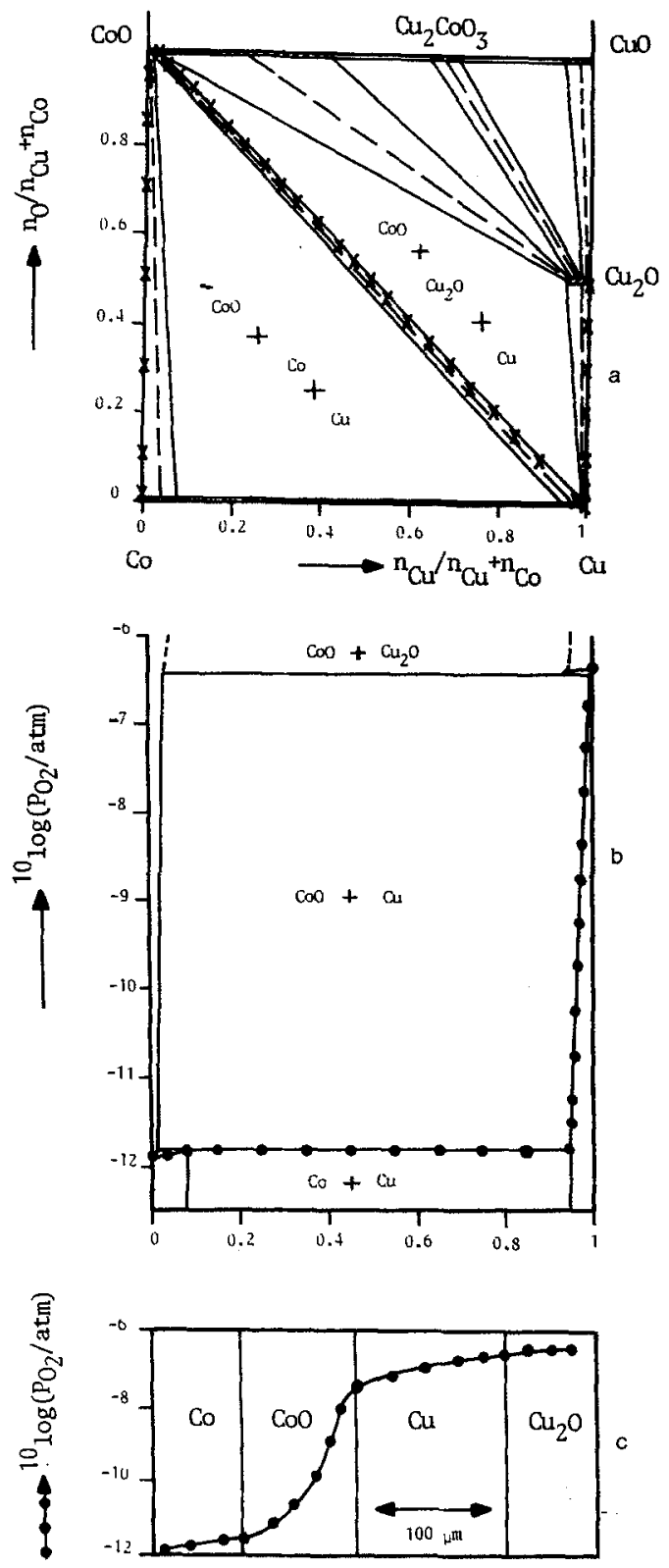

Fig. 7. (a) Phase relations and diffusion path in the $\mathrm{Co}-\mathrm{Cu}-\mathrm{O}$ system at $1000^{\circ} \mathrm{C}$. (b) The oxygen pressure as a function of the metal mole ratio. The dots represent the oxygen pressure in equilibrium with the solid solutions $\mathrm{Cu}(\mathrm{Co})$ and $\mathrm{Co}(\mathrm{Cu})$. (c) A schematic representation of the layer morphology and equilibrium oxygen pressure in the couple $\mathrm{Co} / \mathrm{Cu}_{2} \mathrm{O}$ after a heat treatment of $100 \mathrm{hr}$ at $1000^{\circ} \mathrm{C}$. 

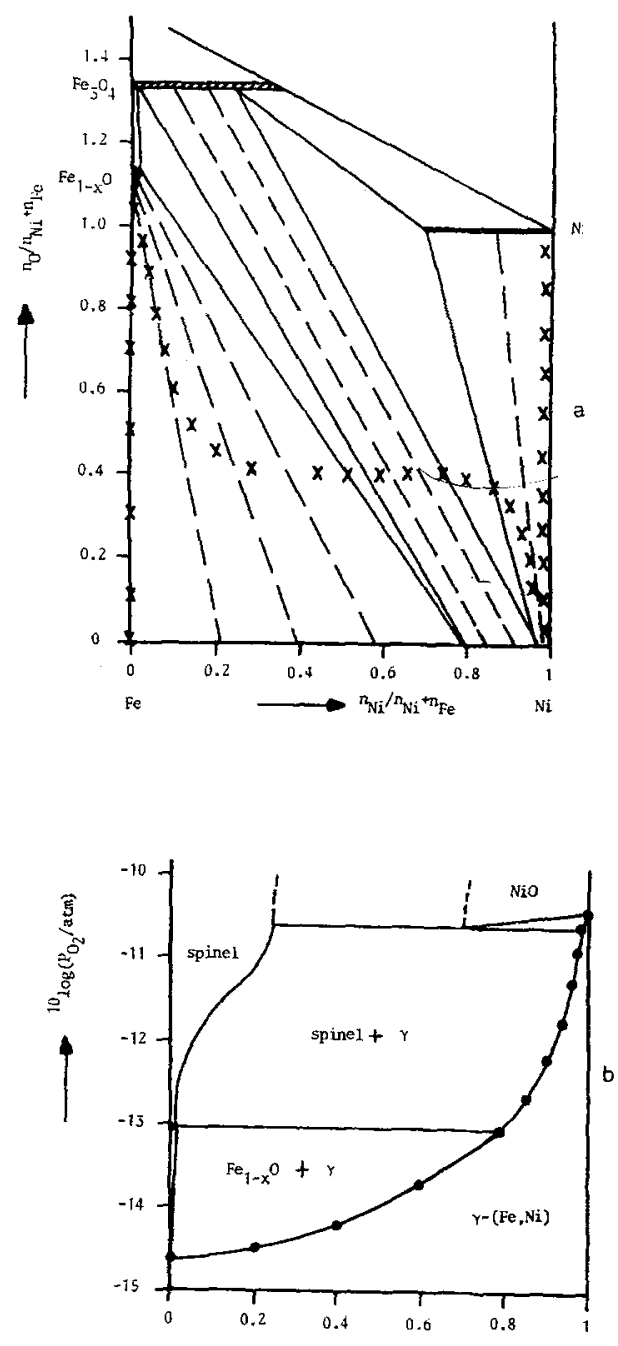

Fig. 8. (a) Phase relations and diffusion path in the $\mathrm{Fe}-\mathrm{Ni}-\mathrm{O}$ system at $1000^{\circ} \mathrm{C}$. (b) The oxygen pressure as a function of the metal mole ratio. The dots represent the oxygen pressure in equilibrium with the $\gamma$ solid solution. (c) A schematic representation of the layer morphology and equilibrium oxygen pressure in the couple $\mathrm{Fe} / \mathrm{NiO}$ after a heat treatment of $100 \mathrm{hr}$ at $1000^{\circ} \mathrm{C}$.

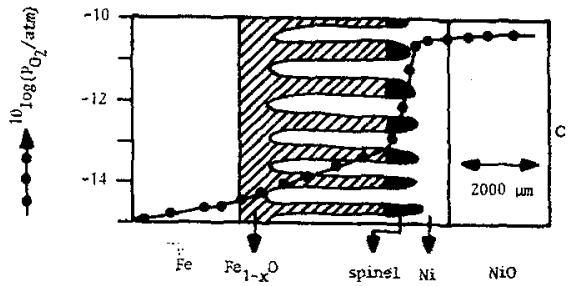



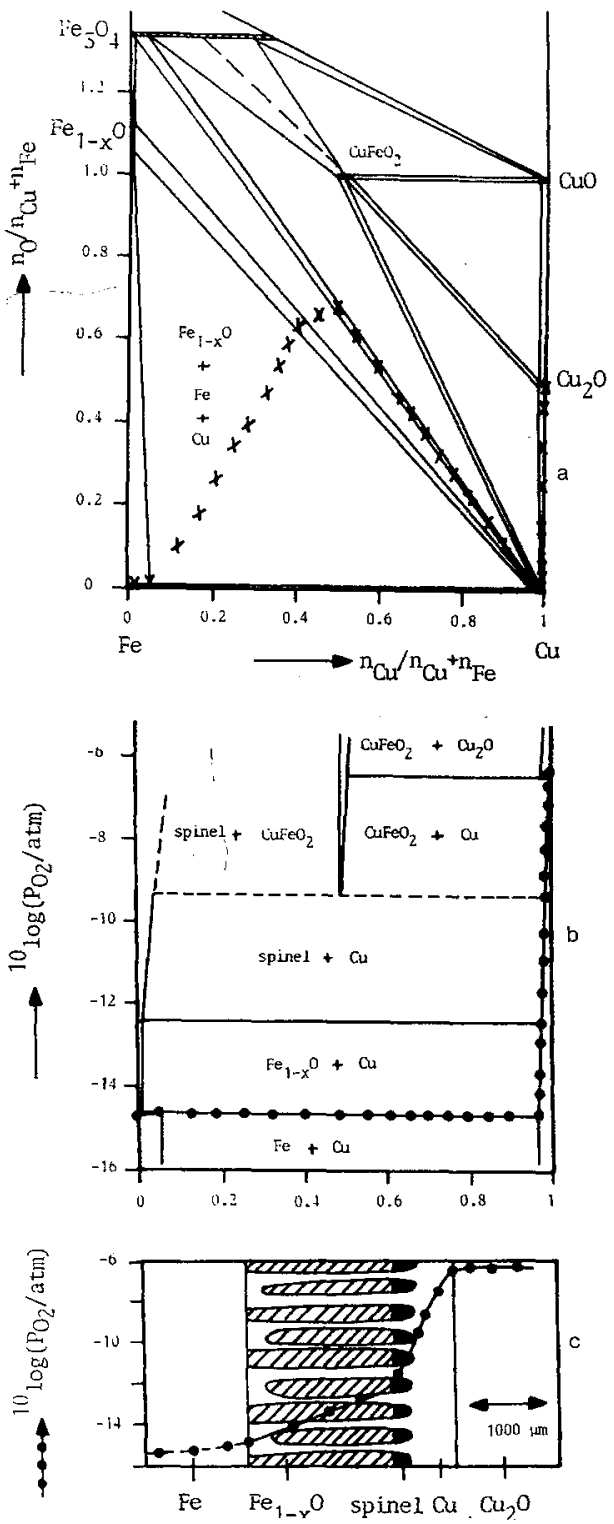

Fig. 9. (a) Phase relations and diffusion path in the $\mathrm{Fe}-\mathrm{Cu}-\mathrm{O}$ system at $1000^{\circ} \mathrm{C}$. (b) The oxygen pressure as a function of the metal mole ratio. The dots represent the oxygen pressure in equilibrium with the solid solutions $\mathrm{Fe}(\mathrm{Cu})$ and $\mathrm{Cu}(\mathrm{Fe})$. The dashed lines represent estimated values. (c) A schematic representation of the layer morphology and equilibrium oxygen pressure in the couple $\mathrm{Fe} / \mathrm{Cu}_{2} \mathrm{O}$ after a heat treatment of $100 \mathrm{hr}$ at $1000^{\circ} \mathrm{C}$. 

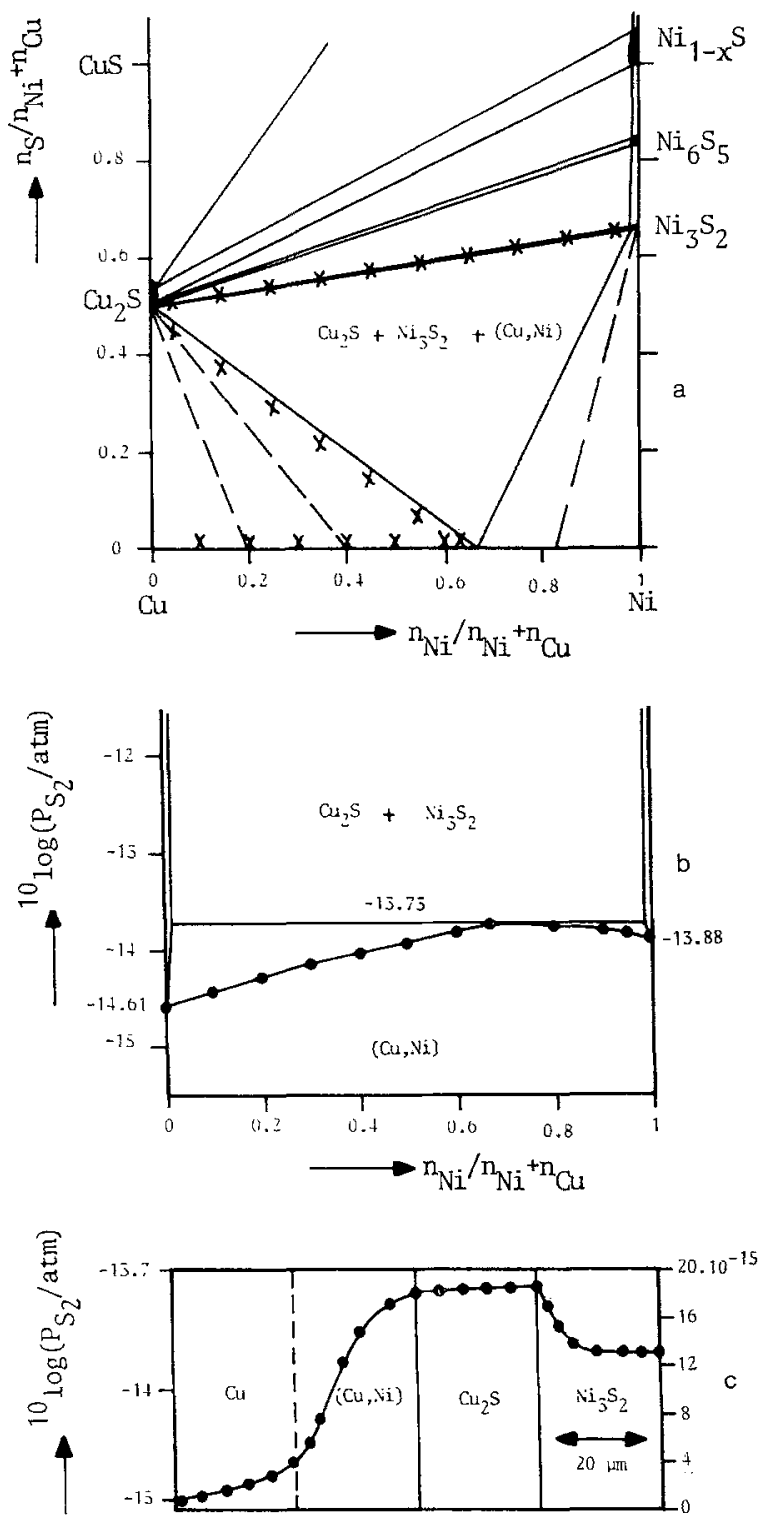

Fig. 10. (a) Phase relations and diffusion path in the $\mathrm{Cu}-\mathrm{Ni}-\mathrm{S}$ system at $500^{\circ} \mathrm{C}$. (b) The sulfur pressure as a function of the metal mole ratio. The dots represent the sulfur pressure in equilibrium with the solid solution $(\mathrm{Cu}, \mathrm{Ni})$. (c) A schematic representation of the layer morphology and equilibrium sulfur pressure in the couple $\mathrm{Cu} / \mathrm{Ni}_{3} \mathrm{~S}_{2}$ after a heat treatment of $100 \mathrm{hr}$ at $500^{\circ} \mathrm{C}$. 

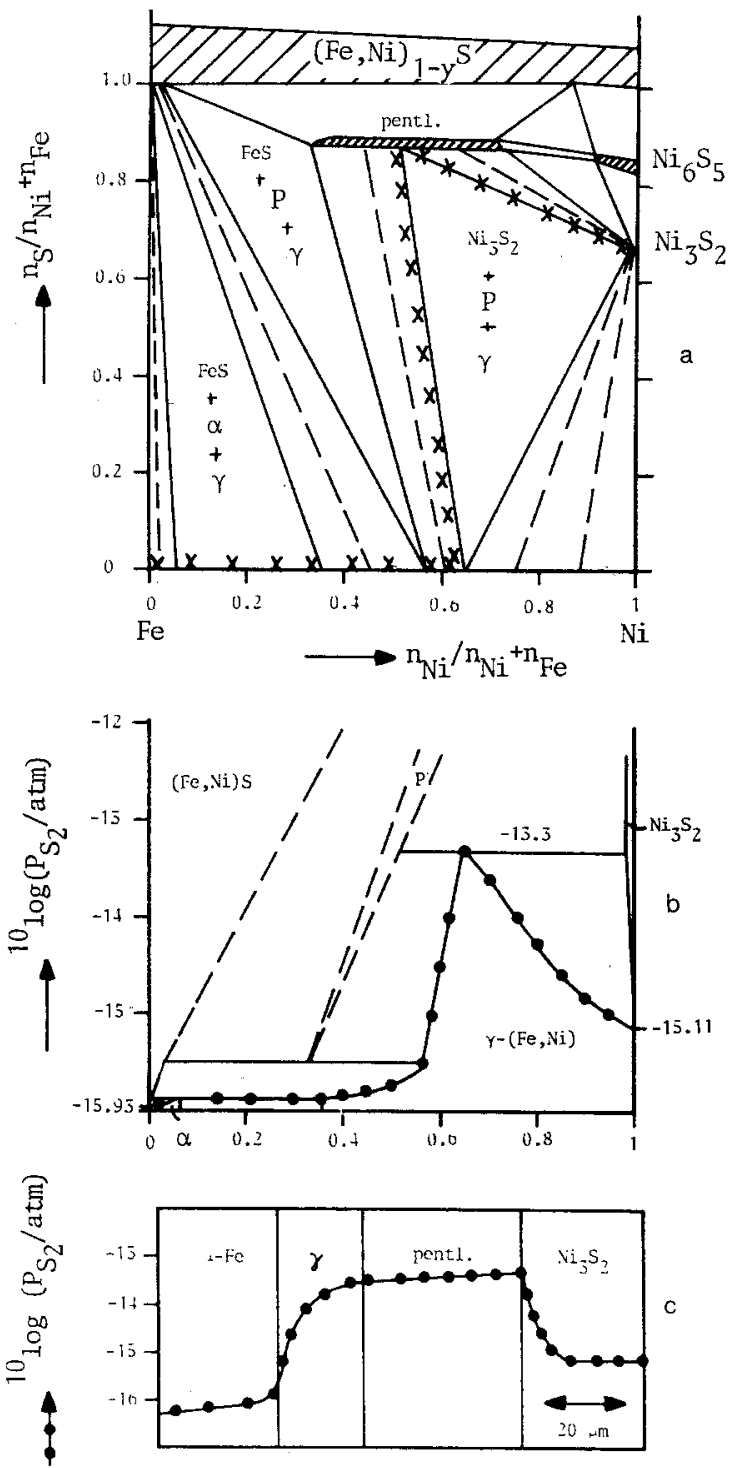

Fig. 11. (a) Phase relations and diffusion path in the $\mathrm{Fe}-\mathrm{Ni}-\mathrm{S}$ system at $460^{\circ} \mathrm{C}$. (b) The sulfur pressure as a function of the metal mole ratio. The dots represent the sulfur pressure in equilibrium with the solid solutions $\alpha$ and $\gamma$. The dashed lines represent estimated values; $\mathrm{P}=$ pentlandite. (c) A schematic representation of the layer morphology and equilibrium sulfur pressure in the couple $\mathrm{Fe} / \mathrm{Ni}_{3} \mathrm{~S}_{2}$ after a heat treatment of $100 \mathrm{hr}$ at $460^{\circ} \mathrm{C}$. 


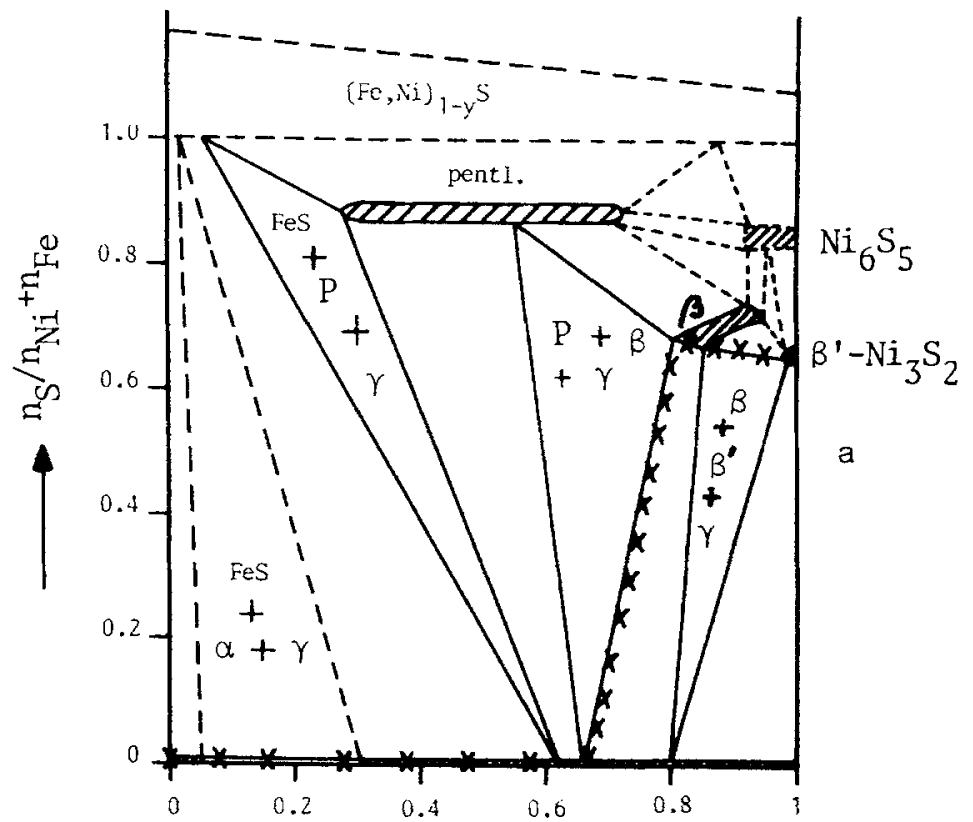

Fe

$\longrightarrow \mathrm{n}_{\mathrm{Ni}} / \mathrm{n}_{\mathrm{Ni}}{ }^{+\mathrm{n}_{\mathrm{Fe}}}$

$\mathrm{Ni}$

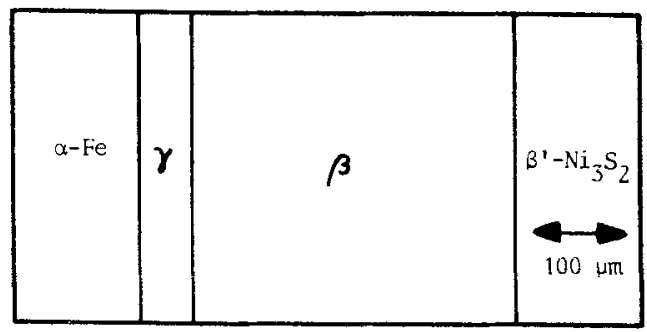

b

Fig. 12. (a) Phase relations and diffusion path in the $\mathrm{Fe}-\mathrm{Ni}$ $\mathrm{S}$ system at $500^{\circ} \mathrm{C}$. The dashed parts are not experimentally verified and are based on estimations. ${ }^{1}$ (b) A schematic representation of the layer morphology in the $\mathrm{Fe} / \mathrm{Ni}_{3} \mathrm{~S}_{2}$ couple after a heat treatment of $100 \mathrm{hr}$ at $500^{\circ} \mathrm{C}$.

\section{Metallic Systems}

From earlier experiments on phase relations and diffusion paths in metallic systems, two displacement reactions can be mentioned, viz., the reactions $\mathrm{Ni} / \mathrm{Cu}_{7} \mathrm{Ti}_{2}$ (ref. 16) and $\mathrm{Ni} / \mathrm{Fe}_{2} \mathrm{Ti}$ (ref. 17). In the first case a 

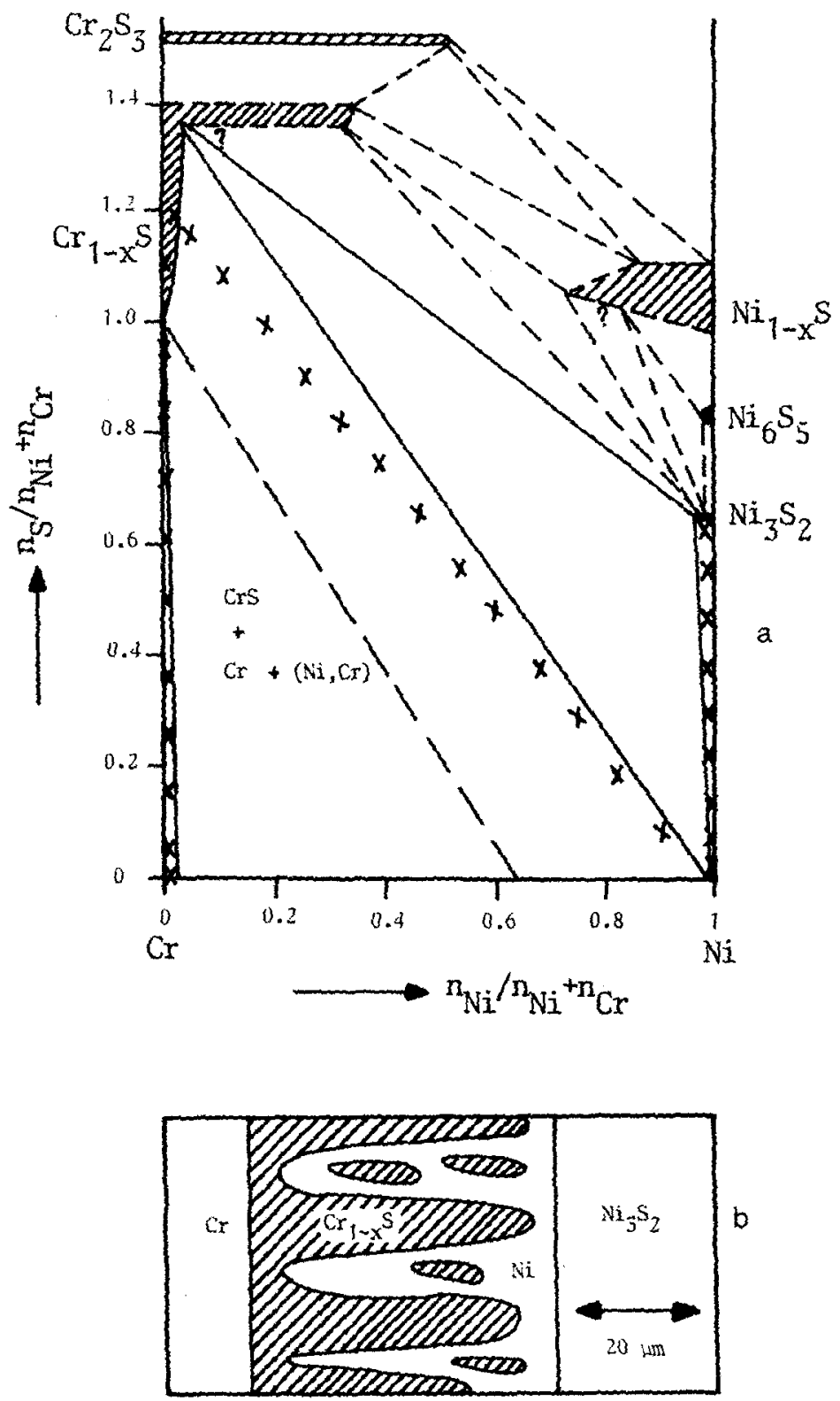

Fig. 13. (a) Tentative phase relations in the $\mathrm{Cr}-\mathrm{Ni}-\mathrm{S}$ system at $500^{\circ} \mathrm{C}$ together with the diffusion path. (b) A schematic representation of the layer morphology in the $\mathrm{Cr} / \mathrm{Ni}_{3} \mathrm{~S}_{2}$ couple after a heat treatment of $100 \mathrm{hr}$ at $500 \mathrm{C}$. 
layered morphology of the type $\mathrm{Ni} / \mathrm{NiTi}_{3} / \mathrm{Cu} / \mathrm{Cu}_{7} \mathrm{Ti}_{2}$ was found in agreement with the constant negative sign of the slope of the relevant tie-lines. In the second case the sign of the slope varies from positive to negative, and in accordance with this, the layer sequence was of the type $\mathrm{Ni} /(\mathrm{Ni}, \mathrm{Fe}) / \mathrm{NiTi}_{3} / \mathrm{FeTi}_{2}$. Because of the more complex nature of these reactions, a more detailed discussion on these and other systems will be published separately.

In any case these examples show the general character of the proposed model. In fact, every diffusion path in a multiphase ternary system has to obey the rules imposed by this model regardless whether the reaction is of the displacement type or not. Therefore, diffusion paths can partly be predicted, at least in the sense that a number of possibilities can be ruled out on the basis of the course of the tie-lines in the phase diagram.

\section{SUMMARY}

We have developed a model on the basis of the thermodynamics of a ternary system which allows us to predict in displacement reactions the initial layer sequence, or at least to exclude other types of sequences of the reaction products. The slope of the tie-lines in the ternary phase diagram is indicative for the initial layer sequence in the diffusion couple. The essential statement is that no element will intrinsically diffuse into a direction where it own activity will be raised. This general requirement is not limited to displacement reactions, and therefore diffusion paths in other types of reaction can also at least be partly predicted. Morphological variants of the thermodynamically predicted initial layer sequence may develop on kinetic grounds.

\section{REFERENCES}

1. J. A. van Beek, P. M. T. de Kok, and F. J. J. van Loo, Oxid. Met. 22, 147 (1984).

2. R. A. Rapp, A. Ezis, and G. J. Yurek, Met. Trans. 4, 1283 (1973).

3. G. J. Yurek, R. A. Rapp, and J. P. Hirth, Met. Trans. 4, 1293 (1973).

4. A. D. Pelton and H. Schmalzried, Met. Trans. 4, 1395 (1973).

5. J. E. Lane and J. S. Kirkaldy, Can. J. Phys. 42, 1643 (1964).

6. M. A. Dayanada and C. W. Kim, Met. Trans. A10A, 1333 (1979).

7. P. J. C. Vosters, M. A. J. Th. Laheij, F. J. J. van Loo, and R. Metselaar, Oxid. Met. 20, 147 (1983).

8. P. J. C. Vosters, Internal Report THE, Dept. Chemical Technology, Eindhoven, 1982 (in Dutch).

9. O. Kubaschewski, E. L. L. Evans, and C. B. Alcock, Metallurgical Thermochemistry, (Pergamon Press, London, 1967).

10. I. Barin and O. Knacke, Thermochemical Properties of Inorganic Substances (SpringerVerlag, Berlin, 1973).

11. I. Barin, O. Knacke, and O. Kubaschewski, Thermochemical Properties of Inorganic Substances, Supplement (Springer-Verlag, Berlin, 1971). 
12. M. A. J. Th. Laheij, F. J. J. van Loo, and R. Metselaar, Oxid. Met. 14, 207 (1980).

13. J. S. Kirkaldy, G.-M. Bolze, D. McCutcheon, and D. J. Young, Met. Trans. 4, 1519 (1973).

14. R. H. Lin, D. C. Hu, and Y. A. Chang, Met. Trans. B9B, 531 (1978).

15. S. R. Shatynski, J. P. Hirth, and R. A. Rapp, Met. Trans. A10A, 591 (1979).

16. F. J. J. van Loo, G. F. Bastin, and A. J. H. Leenen, J. Less-Com. Met. 57, 111 (1978).

17. F. J. J. van Loo, J. W. G. A. Vrolijk, and G. F. Bastin, J. Less-Com. Met., 77, 121 (1981). 